Rhode Island College

Digital Commons @ RIC

Master's Theses, Dissertations, Graduate

Master's Theses, Dissertations, Graduate

Research and Major Papers Overview

Research and Major Papers

$1-1-2014$

\title{
Examining Chronic Stress in Spouses of Active Duty Military \\ Members
}

Cristina L. Joseph

Rhode Island College

Follow this and additional works at: https://digitalcommons.ric.edu/etd

Part of the Other Mental and Social Health Commons, Other Nursing Commons, and the Psychiatric and Mental Health Commons

\section{Recommended Citation}

Joseph, Cristina L., "Examining Chronic Stress in Spouses of Active Duty Military Members" (2014).

Master's Theses, Dissertations, Graduate Research and Major Papers Overview. 240.

https://digitalcommons.ric.edu/etd/240

This Major Paper is brought to you for free and open access by the Master's Theses, Dissertations, Graduate Research and Major Papers at Digital Commons @ RIC. It has been accepted for inclusion in Master's Theses, Dissertations, Graduate Research and Major Papers Overview by an authorized administrator of Digital Commons @ RIC. For more information, please contact digitalcommons@ric.edu. 


\title{
EXAMINING CHRONIC STRESS IN \\ SPOUSES OF ACTIVE DUTY MILITARY MEMBERS
}

\author{
by \\ Cristina Joseph \\ A Major Paper Submitted in Partial Fulfillment \\ of the Requirements for the Degree of \\ Masters of Science in Nursing \\ in \\ The School of Nursing \\ Rhode Island College
}

2014 


\begin{abstract}
Even in the absence of wartime stressors, the military lifestyle is characterized by frequent challenges that affect not only the military member, but also his or her spouse and children. Due to frequent relocations and deployments, military spouses are often relied upon to become the primary child-rearers, make occupational sacrifices, deal with financial concerns independently, organize relocations, and cope with lack of social support. These multiple responsibilities can create a myriad of stressors, which over time lend themselves to the formation of chronic stress. The purpose of this exploratory study is to determine if spouses of active duty military members display chronic stress according to the Trier Inventory for the Assessment of Chronic Stress (TICS-LE). Seventy-one female military spouses responded to the TICS-LE online. Mean scores for all the factors on the TICS-LE ranged between 1.03 and 2.05, which was lower than expected given the plethora of stressors associated with the military lifestyle. Findings suggested that chronic stress levels experienced by military spouses may be mitigated by high quality social support systems, the demographic factors of the military spouse and whether the military family has developed resilience after years of being embedded in the military lifestyle. This major paper project underscores the need for advanced practice nurses to be aware of the multiple stressors that military spouses face, unique cultural phenomena present in military life, and its possible implications on the psychological and physical functioning of military spouses.
\end{abstract}




\section{Acknowledgements}

I would like to express my gratitude to my advisor, Patricia A. Molloy, Ph.D. APRN, BC, for her hard work and guidance in bringing this masters paper project to fruition. In addition, I would like to thank my second and third readers, Judith Murphy, Ph.D., RN and Kyle Gamache, LHMC, for their additional input and sage advice. I am also sincerely thankful to Dr. Wolfe Schlotz at the University of Trier (Trier, Germany) who graciously loaned me the Trier Inventory for the Assessment of Chronic Stress to complete this project. Finally, I would like to thank my family for all the continuous love and support they have provided me in the last year, which was a tremendous help in completing this project. 


\section{Table of Contents}

Table of Contents........................................................

Statement of the Problem................................................................

Theoretical Framework.......................................................4

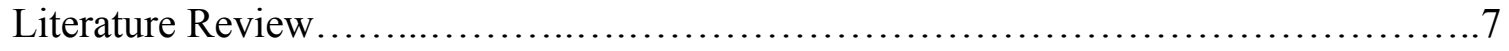

Method................................................................... 17

Results.................................................................20

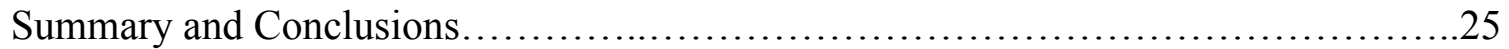

Recommendations and Implications for Advanced Nursing Practice....................32

References.................................................................. 36

Appendices................................................................ 40 


\section{Statement of the Problem}

More than two million military members have been deployed to Iraq and Afghanistan since 2001 in Operation Iraqi Freedom and Operation Enduring Freedom (OIF and OEF, respectively) (De Burgh, White, Fear, \& Iversen, 2011). Both OEF and OIF were lengthy conflicts that used only volunteer military members and resulted in multiple, as well as, lengthy deployments for service members and families. Presumably, due to improvements in battlefield medicine, fewer military personnel have died in battle, but more military members have returned home wounded from these prolonged conflicts than at any other point in the history of U.S. conflicts abroad (Asbury \& Martin, 2011). Not only have these conflicts been challenging as a nation, but OEF and OIF have been profoundly salient events for military families resulting in a demanding set of circumstances.

Although deployment stressors receive a great amount of attention in the media, even in the absence of deployment and wartime stressors, the military lifestyle is characterized by frequent challenges that affect not only the military member, but also his or her spouse and children. Active duty military families are required to relocate, on average, every 2-3 years, which can disrupt the families' support networks, the military spouse's socialization, and the child's education (Lowe, Adams, Browne, \& Hinkle, 2012). In addition, frequent moves often disrupt the military spouse's ability to find employment or complete educational programs. According to the National Military Family Association (2007), one third of spouses stated that it was taking more than five years to complete a degree program, with reports of job changes, difficulty transferring 
credits, frequent moves, and deployments hindering progress toward degree completion. Even during peacetime, the threat of deployment still looms for active duty military members, as does the requirement that the military member leave the family unit for short periods of time, such as temporary duty assignments and training exercises. Children are also affected by these frequent relocations. Hiew (1992), who studied elementary schoolage children whose fathers were absent for prolonged periods of time, observed psychological illness, behavior problems, and poor academic achievement in these children.

Frequent moves also make it unlikely that military spouses will reside nearby their extended family, which can limit the availability of childcare and social supports. The lack of social support is particularly challenging in these situations. Lowe et al. (2012) argued that "the armed forces maintain their own diverse cultural, demographic, and personal constructs" (p. 17), which may be poorly understood by the general public and can further isolate relocated military spouses from the civilian world. Due to this difficult lifestyle, military spouses are often relied upon to become the primary childrearers, make occupational sacrifices, deal with financial concerns independently, organize relocations, and cope with lack of social support. The military spouse not only has to juggle these multiple roles, but actually has to provide an anchor-like stabilizing role in military families. Green, Nurius, \& Lester (2013) argued that the military spouse "holds the keystone role in establishing and maintaining an environment conducive to the needs of both child and adults" (p. 756). These multiple roles and responsibilities, in 
addition to the potential absence of social supports in light of constant relocation, beg the question of whether military spouses experience chronic stress.

Much of the existing literature on chronic stress in the military examines spouses' acute stress during particularly trying times, like deployment, or the preponderance of psychological illness and coping mechanisms in this population. However, a dearth of literature examines the cumulative effects of the military lifestyle upon the military spouse. The purpose of the study is to determine if spouses of active duty military members display chronic stress according to the Trier Inventory for the Assessment of Chronic Stress (TICS-LE). Although multiple definitions of chronic stress exist, Schulz, Schlotz, \& Becker (2011) discussed four characteristics of chronic stress: it “(1) has a nonspecific subtle onset, (2) can be of long or short duration, (3) is often characterized by reoccurring stressors, and (4) may have a low or high intensity" (p. 5). 


\section{Theoretical Framework}

In 1936, Hans Selye was the first researcher to introduce the concept of stress (Rice, 2012). His discovery stemmed from his work using laboratory rats; Selye noted that when the rats were injected with various noxious stimuli (stressors) such as cold, heat, and hormones, the rats displayed similar patterns of disease. Selye labeled this pattern of responses to stressors the General Adaptation Syndrome (GAS), which consisted of three phases: an alarm reaction, a stage of resistance, and finally a stage of exhaustion. Seyle defined the concept of 'stress' as "a state manifested by a specific syndrome which consists of all the nonspecifically induced changes within the biological system" (Rice, 2012, p. 23).

Many years later, the connection between stress and chronic illness has been well established; chronic stress has been linked to decreased immune function, increased inflammation, and activation of the sympathetic nervous system (Groer, Meagher \& Kendall-Tackett, 2010). Furthermore, stress has been associated with cardiovascular, neurogenerative, and autoimmune diseases (Groer, Meagher \& Kendall-Tackett, 2010). An underpinning theoretical framework that explains the linkage of chronic stress with physical disease is McEwen's (1998) conceptual framework of allostasis and allostatic load. According to McEwen, the body attempts to achieve allostasis, or a state of internal balance, through change. When a threatening stimulus is introduced, the human body activates a complex array of neurohormonal pathways to deal with noxious stimuli. Short-term activation of these neurohormonal pathways is normal; however, long-term activation, such as being in a state of chronic stress, can have deleterious effects on the 
cardiovascular, metabolic, and immunologic systems. Long-term, harmful activation of the body's stress response can be described as allostatic load.

McEwen suggested that there are four ways in which the body is challenged by allostatic load. Firstly, an individual may have stressors that are simply too frequent and unrelenting to adapt to - such as in chronic stress. Secondly, an individual may lack the ability to adapt to a particular stressor, such as an inability to calmly give an oral presentation in front of a group of peers. Thirdly, an individual may be exposed to a stressor, but have difficulty returning to baseline after the stressor is removed. McEwen proposed that after decades of allostatic load, the body's neurohormonal pathways, which drive the stress response, no longer respond adequately. The fourth type of allostatic load occurs when the lifetime level of allostatic load becomes too burdensome and the body begins to utilize neurohormonal pathways maladaptively.

The concept of allostatic load can be applied to military spouses'stressors, e.g., frequent moves, job changes, spouse deployments and lack of family support are all challenges that may contribute to allostatic load. Furthermore, McEwen suggested that there are multiple ways in which an individual, such as a military spouse, can fail to cope with these stressors. Stressors may be too incessant and relentless, such as the disruption of the family unit when a military member has frequent and multiple deployments; or a military spouse lacks the ability to adapt to a particularly trying stressor, such as organizing a household relocation independently.

McEwen warns that failure to adapt to stressors disrupts neurohormonal pathways and eventually results in disease. Current literature has addressed how stressors 
associated with the military lifestyle have been linked to not only physical disease, but psychological disease and impaired family functioning. The next section presents a literature review on the effects of chronic stress on those in the military and their families. 


\section{Literature Review}

A literature review review was conducted using Academic Search Premier and Cumulative Index to Nursing and Allied Health Literature (CINAHL) with the keywords “military spouse", “deployment”, "stress" and "long-term.” The literature review was limited to articles completed in the last ten years that were available in English. After examination of the literature, three major areas of study were identified: the impact of military lifestyle on the family unit, the physical health of military spouses, and the psychological health of military spouses during deployment.

\section{Military Lifestyle and the Family Unit}

One of the most prominent issues among military families that makes them unique is that the military member is absent from the family unit in both the long and short term for deployment, temporary duty assignments, and frequent trainings (Lowe et al., 2012). Lowe et al. (2012) explored how an active duty military member's absence affects family stress (specifically, the parent-child relationship), as reported by the spouse. In this qualitative/quantitative study, the authors administered the Parenting Stress Index and Parenting Relationship Questionnaire to Air Force spouses. The purpose of the study was to determine if extended absences or length of time in the military was associated with increased total stress. The researchers found that relationships between the dependent spouse and children were negatively affected by both longer and shorter periods of deployment, despite the fact that dependent spouses who were affiliated with the military for longer periods of time reported less stress within the parent-child 
relationship. The combination of weak parent-child communication and shorter periods of 'time away' also resulted in increased parental stress.

The authors presented several possibilities for these findings which included: 1) a period of adjustment that the family unit undergoes when a family member joins the military, 2) the military spouse being distracted by an increase in responsibilities during deployment that compete with activities/interactions that would foster relationship cohesiveness, and 3) the need for military spouses to keep family stressors private due to fear of associated negative consequences on career advancement. Regardless of causes, the researchers concluded that those working with military families need to be aware of the negative results that deployment has upon family functioning. The study, however, was limited in that it involved only Caucasian females married to military members in the United States Air Force, therefore results are not generalizable to the larger military population.

Unlike Lowe et al. (2012), who concentrated on the dynamic between the military spouse and the child, Asbury and Martin (2011) focused on the depression, anxiety, social support, and marital discord levels of military spouses versus civilian spouses. In this quantitative study, participants were recruited via a distance learning class and completed the Military Deployment Survey and the Depression and Anxiety Stress Scale online. On the measures of depression and anxiety, both groups reported low levels of depression and anxiety; however, in terms of social support, military spouses reported significantly higher social support levels than civilian spouses. This result was contrary to the authors' hypothesis and anecdotal evidence that military spouses lack sufficient 
support; however, on the measure of marital discord, military spouses reported significantly higher levels of marital discord than civilian spouses. The study revealed a nearly five-fold increase in the percentage of military spouses regularly considering divorce even after controlling for other variables, such as number of children and years married. The authors discussed the need for further investigation into the issue of marital discord and how it pertains to military spouses and families.

Green et al. (2013) examined the military family as a unit and compared military families' stressors to a normative population sample, operating under the assumption that the military spouse "holds the keystone role in establishing and maintaining an environment conducive to the needs of both child and adults" (p. 756). The study examined the stressors and psychological health of military families, adopting the stance of McCubbin and Patterson (1982), who argued that such stressors have the ability to "pile-up" during times of prolonged separation.

Green et al. (2013) compared the stressors and resources of military families to civilian families, assessed how certain events influenced a spouse's psychological health, and lastly, examined to what degree social and socioeconomic resources and family strain influenced a spouse's psychological health. One hundred seventy-one female partners of active duty Army and Marine servicemen were interviewed and administered a series of self-report scales. The study noted that military spouses had higher levels of general psychological distress than normative civilian counterparts. More specifically, spouses who displayed psychological distress also indicated lower levels of educational and economic resources. The spouses who reported not graduating from college also 
described having difficulty managing finances, having children at an early age, lack of social support, and significantly higher levels of psychological distress and family stress. After analysis, the only variable that was significantly linked to the spouse's psychological health was social support, which alleviated depressive symptoms in this study. The researchers concluded that a number of military spouses - and arguably whole family units - are struggling to maintain stability in the household.

On a similar note, Herzog, Everson, \& Whitworth (2011) conducted an exploratory study examining if post-traumatic stress disorder (PTSD) present in the military member could have a "trickle-down effect" on children and military spouses, who may exhibit secondary stress symptoms. Results suggested that the concept of secondary stress trauma exists in families; however, most importantly, the military spouse may play a key role in mitigating secondary traumatic stress symptoms in children.

\section{Physical Health of Military Spouses}

Padden, Connors, and Agazio (2011) studied female military spouses' stress levels and health promotion behaviors while their husbands were deployed. One hundredfive military spouses were recruited at Family Readiness Groups and administered the Perceived Stress Scale and the Modified Health Behavior Inquiry. The purpose of the study was to describe how well-being, perceived stress and coping behaviors affects female spouses of active duty military members during deployment. Using the Perceived Stress Scale, researchers found that stress was marginally increased during a spouse's deployment as compared to a normative sample of American woman. Military spouses 
appeared to feel their stress levels were not insurmountable; sixty percent of spouses studied denied feeling that stressors were insurmountable (Padden et al., 2011). Researchers found that on some measures, the stress present during deployment was associated with some decreases in health promotion behaviors including use of tobacco products, which was found to be high in military spouses as compared with the general population as calculated in Health People 2010 objectives. In contrast, compared to rates reported in Healthy People 2010 objectives, military spouses in the sample appeared to be more physically active.

Burton, Farley, and Rhea (2009) investigated the link between stress and physical health by comparing stress and somatization in spouses of deployed and non-deployed military members. The researchers recruited 130 female participants and divided them into two groups: deployed and non-deployed. The participants with a deployed spouse displayed significantly higher perceived stress scores than the non-deployed spouse group. In addition, Burton et al. (2009) described a significant correlation between stress levels (using the Perceived Stress Scale) and somatic complaints as measured by the Patient Health Questionnaire. Some of the most common somatic complaints reported in the study were feeling tired, trouble sleeping, menstrual cramps/problems, feeling your heart pound/race, and having little energy.

\section{Psychological Health of Military Spouses During Deployment}

Joseph and Afifi (2010) explored how military spouses disclose stressful situations to their deployed spouse. The authors were particularly interested in a concept called protective buffering, which was first described by Hagedoorn, Kuijer, Buunk, 
DeJong \& Wobbes (2000) as when a stressor is pertinent to two people in a relationship, but one individual chooses to deal with that stressor individually. Joseph and Afifi (2010) tested several hypotheses to examine how protective buffering would affect other variables such as health, well-being, marital satisfaction, future communication disclosures, and spousal support.

The survey was administered online to 105 female military spouses of service members currently deployed in various branches of the service who had at least one child at home. The results supported the hypothesis that the less participants protectively buffered, the fewer negative health symptoms were reported by military spouses. In contrast, the results did not support the hypothesis that fewer negative health symptoms would be reported if the military spouse disclosed more information to her deployed spouse. In terms of communication, the more stressors that were disclosed to husbands, the more content the couple was with their relationship, even after controlling for the amount of communication. However, the authors also found that the more spouses communicated during deployment, the less satisfied the wife was with the relationship. Joseph and Afifi (2010) attributed this enigmatic finding to a change in the dynamic of the spousal relationship, with tensions arising from the wife becoming more independent due to deployment. As predicted, the authors found that if wives perceived their spouse to be in danger, the more wives were restrained in disclosing stressful information. The practice of protective buffering - if the husband was perceived to be in danger - increased if the wife was older or if the husband had been in the service for a short time. In terms of social support, the authors found that if military wives perceived their husbands to be 
supportive, the less the wives practiced protective buffering. Surprisingly, Joseph and Afifi (2010) also found that social support from the military community did not influence the likelihood that wives would share stressors with their spouse. The study was limited by a sample of female spouses who were primarily Caucasian and results were not generalizable; however, the study suggested that communication patterns likely change between spouses during deployment with stressors being shared only during specific circumstances.

In a slightly different vein, Lapp et al. (2010) examined stress and coping in spouses of National Guard and National Reserve members during deployment. In this qualitative study, the researchers performed open-ended interviews with 18 spouses: 16 women and 2 men. The study investigated common themes among spouses regarding stress and coping in all the stages of deployment: pre-deployment, during deployment, and post-deployment. The pre-deployment phase was characterized by uncertainty of plans and inability to make plans. During deployment, spouses reported worrying about the deployed spouse's safety, how deployment might change the spousal relationship, and how deployment would affect childrearing practices. In addition, spouses reported a drive to remain connected via technology with the deployed spouse. Deployment resulted in additional stressors of managing extra household duties and managing finances; some spouses reported decreased income and increased financial stress, because the deployed spouse had lost previous employment. Lapp et al. reported that spouses who were left behind effectively became single parents; however, the participants reported that they felt they had less support and resources than typical single parents. For some participants, 
being the sole child rearer was described as an overwhelming responsibility, and sleep deprivation was reported by many participants in the study. Finally, the authors described the post-deployment phase as a time of readjustment. Spouses acknowledged that military members could return as different people changed by the experiences while deployed. Other participants reported that their spouses seemed bothered and changed by their military experience, but were unwilling to share these experiences, which left the military spouses feeling incapable.

In a similarly designed study, Wheeler and Torres Stone (2009) examined stress and coping strategies during deployment in National Guard spouses. Wheeler and Torres Stone argued that National Guard spouses are particularly ill-equipped for deployment, because ties to the military lifestyle are weak, and deployment, especially multiple and prolonged deployments, are unexpected. The researchers conducted nine semi-structured interviews; convenience sampling was used and all participants were well-educated, Caucasian females. Wheeler and Torres Stone found nearly identical stressors and coping mechanisms as those mentioned in other studies: spouses expressed emotional lability, fear the military member could be harmed, difficulty concentrating, and feelings of anger and anxiety. One unique finding in the study was the concept of a "broken promise," which was defined as a "sense that the military did not use the National Guard in the manner in which it should" (Wheeler \& Torres Stone, 2009, p. 548). Furthermore, military spouses described shock at deployment, reservations regarding future involvement with the National Guard, and frustration over a sudden change in lifestyle. Some participants reported frustration that National Guard involvement was expected to 
be short and limited, but due to deployment, had become burdensome. Participants described coping strategies that were similar to those mentioned in other studies, such as journaling, artistic endeavors, support from family and friends, and use of technology to contact the military member.

Two novel themes were identified by Wheeler and Torres Stone (2009), one of which was the use of "avoidance type behavior," which was described as throwing oneself into work or another activity to avoid the reality of the military member's deployment. The second novel theme was that spouses reported increased awareness over current events and political happenings. Increased awareness also extended into the spouses personal lives, and participants stated that deployment helped them realize what was important in their life, changed their personal life perspectives, and increased the respect participants had for single parents.

Another study by Mansfield et al. (2010) examined the incidence of mental health disease in U.S. Army wives during deployment. In this large retrospective chart review of numerous military spouses' records, the authors explored outpatient appointments from 2003-2006. The study included female spouses between the ages of 18 and 48 years old who had been married to a military member in the U.S. Army for at least five years. Data were divided into three groups: spouses with a military member deployed for 1-11 months, spouses with a military member deployed 11 months or more, and spouses with non-deployed military members. Mansfield et al. (2010) found that spouses with deployed husbands displayed higher rates of depressive disorders, sleep disorders, anxiety disorders and acute stress reactions when compared to rates of military spouses 
without a deployed spouse. Furthermore, the rate of new psychiatric diagnoses continued to rise if the military member was deployed 11 months or more.

Two noteworthy limitations of the study was the author's decision to eliminate male spouses and race and ethnic demographic information from the study due to issues with statistical analysis. The sample of men, which consisted of only $5 \%$ of the total study population, did not exhibit a similar pattern of variance in psychological issues and demographics; therefore, there were concerns that data from this group would not be generalizable. In addition, race and ethnic demographic information was not reliably available to researchers in the medical record, therefore race and ethnic information was excluded from statistical analysis. Both limitations prevent generalization of the results and curb understanding of how men and racial minorities psychologically deal with deployment.

In conclusion, much of the existing literature focuses on deployment and how it affects the family dynamic, as well as the physical and emotional health of the military spouse. The literature suggests that the military lifestyle is associated with increased stress however, much of the research concentrates on the episodic stress of deployment and not long term stress that may arise after years of being a member of a military family.

The next section describes the method used by this writer to explore chronic stress in a small sample $(\mathrm{N}=71)$ of female military spouses. The sample, site and general procedures used are included in this next section. 


\section{Method}

The purpose of this descriptive study was to explore military spouses' experiences of chronic stress using the Trier Inventory for the Assessment of Chronic Stress (TICSLE, version 1.0). The TICS-LE is a 57-item scale that measures nine types of stress experienced in the last three months using a Likert scale including: work overload, social overload, pressure to perform, work discontent, excessive demands at work, lack of social recognition, social tensions, social isolation, and chronic worrying (Schulz et al., 2011). The TICS-LE tool has been used primarily in Germany in the German language and was only recently translated into English by the instrument's author. (With the permission of the author, this study represents the first time that the English version of the tool has been used.)

\section{Sample and Site}

Convenience sampling was used to gather participants for this study. Military spouses were recruited at two military spouse clubs in the Northeast, United States. Military spouse clubs are located around military bases and provide opportunities for spouse socialization and informal support. Inclusion criteria for this study included military spouses of any active duty military member in the Navy, Air Force, Marines, and Army. National Guard members were considered eligible to participate if the military member was activated - being on active duty. Participants were required to be female, over the age of 18 and speak English.

Coast Guard spouses were excluded, because the Coast Guard possesses a unique structure that differs from other military branches. During peacetime, the U.S. Coast 
Guard's mission focuses on domestic issues and is under jurisdiction of the U.S.

Department of Homeland Security. During wartime, the U.S. Coast Guard becomes part of the U.S Navy. It was unclear whether this unique structure leads to a vastly different lifestyle for military spouses and whether collecting data from U.S. Coast Guard spouses could lead to confounding results.

\section{Procedures}

The researcher obtained permission from Wolff Schlotz, one of the authors of the TICS-LE scale, to use the TICS-LE for this study. After approval was obtained from the Rhode Island College Institutional Review Board in Fall 2013, the researcher contacted two military club presidents who agreed to allow the researcher to solicit participation in the study via an email invitation. An online instrument was designed by the researcher and the website was altered so the researcher would not collect IP addresses or any other identifiable information. An invitation email containing a brief explanation of the study with an embedded URL link was sent to the military club presidents emphasizing that participation was voluntary. Then, that same email was distributed to all military spouses by the military club presidents. Those military spouses who wished to participate, clicked on the embedded URL and were redirected to the website. Participants were provided an implied consent form that explained the purpose of the study, that participation was voluntary, and that they could withdraw at any time. Demographic information was gathered including: age, number of years of education, number of years as a military spouse, employment status, number of children in the family unit, and whether the military member was currently deployed. Several questions were asked about the military 
member, such as age, rank, enlisted versus commissioned, branch of the military, number of deployments the military member has undergone, and length of deployments. After completing demographic information, participants were then directed to the TICS-LE survey. 


\section{Results}

Seventy-nine female military spouses responded to the survey. Eight participants filled out the demographic information only, so these individuals were eliminated from the results. For the remaining 71 participants, data were entered into the Statistical Package for the Social Sciences (SPSS) version 21 for analysis. Participants had a mean age of 37 years old and a range from 23-53 years old. Participants had been in lengthy relationships with their spouse $-45.1 \%$ of respondents stating they had been in a relationship for 11-20 years and $15.5 \%$ of respondents stating they had been in a relationship for 21 years or more. Data demonstrated that military spouses spent a majority of their married lives while the military spouse was active duty: $46.5 \%$ of military spouses reported being in a relationship while the military member was active duty for $11-20$ years, whereas $12.7 \%$ reported being embedded in the military lifestyle for 21 or more years.

The group of female respondents was highly educated with $47.9 \%$ having a Bachelor's degree, $28.3 \%$ having a Master's degree and 7\% having a Doctoral degree. Despite this high level of education, $63.4 \%$ of respondents were not currently working, $23 \%$ of participants reported working part-time and only $13 \%$ reported working full-time. Approximately, $32 \%$ of participants stated that they had three or more children and that could be one factor that influenced the military spouses' desire to be employed.

Military spouses were also asked to identify demographic information regarding the military member. Military members had a mean age similar to their wives - 38 years old with a range between $25-55$ years old.

The sample consisted of a majority of women married to spouses in the Navy and 
Army: $58 \%$ and $25 \%$ respectively; the remainder of the respondents identified a spouse in the Air Force and Marines. The sample consisted primarily of spouses married to commissioned officers (94.4\%) thus, only a little over $5 \%$ of the sample was made up of women married to enlisted military members.

Additional questions were asked about the rank of the military members and of the commissioned individuals, $86 \%$ stated that they ranked between O3-O5. In the Navy, this ranking equates to the position of Lieutenant (03), Lieutenant Commander (04) and Commander (05) (U.S. Department of Defense, n. d.-a). About 10\% of the sample reported having a rank of O6-O10, which in the Navy equates to the accomplished ranks of Captain (06), Rear Admiral Lower Half (07), Rear Admiral Upper Half (08), Vice Admiral (09), and Fleet Admiral (10) (U.S. Department of Defense, n. d.-a). Of the 5 military spouses married to enlisted military members, $60 \%$ reported having a rank of E5-E6, which in the Navy equates to the rank of Petty Officer $2^{\text {nd }}$ and $1^{\text {st }}$ class respectively (U.S. Department of Defense, n. d.-b).

Since deployment is a significant potential stressor, military spouses were asked questions regarding the couples' experiences regarding deployment. Only $10 \%$ of spouses reported that the military member was currently deployed at the time of the survey. However, $40.8 \%$ of participants reported the military member was deployed three to four times and $31 \%$ of participants reported the military member was deployed five or more times. Finally, the military spouses were asked to identify the total length, in years, the military member had been absent due to deployment: $43.7 \%$ of military members had been absent $1-2$ years, $36.6 \%$ were absent $3-4$ years and $12.7 \%$ were absent 5 years or more. 
(Table 1, Appendix A contains more detail regarding the demographic information.) After completing demographic information, participants responded to the 57-item Trier Inventory for the Assessment of Chronic Stress (TICS-LE, version 1.0), which measured how often stressful events arose during the past three months using a Likert scale where zero indicates "never", one means "rarely", two "sometimes", three means "often" and four indicates "very often".

Retrospective self-report measures that require respondents to recall events that have occurred in the past are not without limitations. For these reasons, such measures may have problems with reliability and validity. Many statisticians believe that these limitations can be overcome if a tool has items with good internal consistency. Previous studies conducted by the tool's authors indicated both good internal and test-retest reliability. Factor analysis was also done (Schulz et al., 2011) and revealed that the 57 questionnaire items could be grouped by ten factors. Table 2, appendix B explains in further detail, which items on TICS-LE correspond with each factor.

The highest possible average scale for each of the factors could be four - in this study, the mean score for all the factors ranged between 1.03 and 2.05. Relative to other scores, the military spouses scored highest on the social overload, social isolation and chronic worrying factors.

The creators of the TICS-LE describe social overload as: a person "reports that he/she is dealing with other people's problems for too long, too often and too intensely, being overly responsible for others, having to pay attention to the welfare of others, and/or constantly adjusting to the needs of others" (Schultz et al., 2011). Thus, social overload 
arises from the onerous amount of responsibilities to care for and be mindful of other individuals. Of the 71 participants, the mean score for this factor was 2.05 , which corresponds to choice of "sometimes" on the Likert scale. However, the standard deviation was .79 for this factor. For the population being studied, responses to items seven, nineteen and thirty-nine that are contained on the social overload factor yielded noteworthy results. Item number seven asked participants to rate how often they "have work to do that involves carrying a lot of responsibility for other people". In this item, $31 \%$ selected "often" and another $20 \%$ selected "very often".

Question thirty-nine, asks participants how frequently they "care for the wellbeing of others". Forty-one percent of respondents selected "very often" with an additional $30 \%$ selecting "often". Finally, on item forty-nine, participants were asked to state how often they encountered "situations in which the well-being of others depends on how well I work" - 28\% selected "sometimes", 27\% selected "often" and 20\% selected "very often" (Schultz et al. 2011).

The next factor where the sample had relatively high scores was the domain of social isolation. Schulz et al. (2011) describe social isolation as a perceived deficiency of social contacts on the part of the subject, which leads to a lack of social resources, such as support or affection. Participants had a mean score of 2.0, which corresponds with the selection of "sometimes". The median score was 1.83 with a standard deviation of 1.05 . Notable items on this factor were questions eleven and fifty-six. Item eleven asked military spouses to describe how often they have "times when I am lonely." Thirty-four percent selected "sometimes", but 38\% stated feeling lonesome "often" or "very often". 
Item fifty-six, asks how often military spouses "have no friends to do things with"; in this item, $41 \%$ of respondent selected "often" or "very often.

The sample scores for chronic worrying were also relatively high. Participants had a mean score of 1.7 with a median score of 1.5 and a standard deviation of 1.01 . The authors of the TICS-LE describe chronic worrying as a form of internal stress over diverse matters that may or may not occur (Schulz et al., 2011). One notable item in this factor was question twenty-five, which asks military spouses how often they are overwhelmed by their worries. Thirty-two percent reported "sometimes" and 18\% reported "often or "very often".

In summary, the military spouses studied displayed a mean score for all the factors between 1.03 and 2.05 with the highest possible average score for each of the factors being 4 . Table 3 in appendix $\mathrm{C}$ contains a summary of the descriptive statistics pertaining to this study. Given the aforementioned stressors associated with the military lifestyle noted in the literature, this range of $1.03-2.05$ is lower than expected. The subsequent section discusses several potential explanations for these results. 


\section{Summary and Conclusions}

Given the large number of stressors associated with the military lifestyle, the range of $1.03-2.05$ (on a scale of $0-4$ ) for the ten factors indicates lower levels of stress than what was anticipated. One explanation for these lower average scores was that the sample, which was rather homogenous, might not be representative of the military spouse population at large. A majority of the sample was comprised of highly educated female spouses of commissioned Naval officers in their late 30's. The couples studied were in lengthy marriages where many years of the marriage took place while the military member was active duty. Roughly one-third of the couples had larger than average sized families reporting three or more children.

The fact that one-third of the military spouses had three or more children may have a bearing not only on why many of the military spouses studied were not currently employed, but, more importantly, why scores for the social overload factor were relatively high. Social overload is a construct that pertains to a burdensome amount of tasks to be mindful of and care for others (Schulz et al., 2011). Elevated scores for social overload may be due to the many childcare responsibilities that military spouses have to perform.

An explanation for why social overload was elevated could be that many of the military spouses were married to somewhat high ranking Naval officers; these highpowered careers might hinder the military members participation in child-rearing activities therefore, much of the childcare duties may fall to the military spouse. Furthermore, since the population studied enjoyed rather lengthy marriages, many of the 
childcare duties were likely defined years ago. Childcare duties likely fell to the parent with the most availability; with active duty military members absent due to multiple deployments, childrearing likely fell to the military spouses. Possibly, these traditional childrearing roles became the accepted norm even when the active duty military member returned home. The idea that the military spouse plays a pivotal role in 'holding down the home front', so that the military member can perform their duties, is echoed in the literature. Green et al. (2013) argued that the military spouse "holds the keystone role in establishing and maintaining an environment conducive to the needs of both child and adults" (p. 756). Furthermore, due to frequent relocation, military spouses might lack the social networks that could help with getting respite from child-rearing activities. In Lapp et al.'s (2010) qualitative study, military spouses with deployed partners stated they effectively became single parents; however, the participants reported that they felt they had less support and resources than typical single parents.

Lack of supportive social networks could also contribute to why the military spouses studied had relatively high results for social isolation. Schulz, Schlotz and Becker (2011) described social isolation as perceived deficiency of social contacts on the part of the subject, which leads to a lack of social resources. Frequent relocations are certainly an obvious explanation for feelings of social isolation; however, the idea that the population studied would have scores indicative of social isolation is somewhat surprising. In this study, subjects were recruited from military support groups; therefore, the population studied was already connected to a social network. Perhaps, the population studied did not find the connections provided by the support groups to be substantial 
enough to relieve feelings of social isolation. In addition, maybe military spouses did not have adequate time to devote to social contacts due to multiple childrearing responsibilities. The population studied had spent a lengthy time in the military lifestyle and after several decades of frequent relocations, it is possible that social networks become fragmented, once well-established social networks disband, and individuals who were once close lose touch.

It is important to note, however, that in the current literature, studies of social support and its role mitigating psychological symptoms had conflicting results. In Green et al.'s (2013) study, which examined how certain variables influenced military spouses' psychological health, social support was found to alleviate depressive symptoms and was the only variable that was significantly linked to the spouses' psychological health. On the other hand, Joseph and Afifi (2010) who examined military spouses' and active duty military members' communication patterns found that social support from the military community did not influence the likelihood that wives would share stressors with their spouses. The crux of the matter may be that it is the perceived quality of the relationships that military spouses have with the social network, not just the presence of a social network, that determines whether the military spouses have feelings of social isolation.

The sample score for chronic worrying was also relatively high; this finding is unsurprising however, given the multiple potential stressors associated with the military lifestyle. Moreover, it is important to remember chronic worrying is a form of internal stress where the sources of stress could be quite diverse and may not involve military stressors (Schulz et al., 2011). Furthermore, no cut-off scores existed to establish a point 
where worrying is deemed excessive therefore, the mean score of 1.7 could indicate a normal level of worrying. Although chronic worrying could exist in this sample, the population studied denied feeling that their worries were overwhelming. In the sample studied, only $18 \%$ of respondents reported that they were "often" or "very often" overwhelmed by their worries.

In conclusion, military spouses displayed a mean score for all the factors between 1.03 and 2.05, which was lower than anticipated based on what has been found in the literature. One possible reason why the military spouses did not score higher on the factors for chronic stress could be resilience. In the population studied, made up of participants who enjoyed lengthy marriages, it is possible that over years of marriage the military spouses developed coping skills to deal with multiple deployments, relocations and the disruptions the military life has on their own personal lives. After decades of marriage, the dynamic lifestyle challenges associated with the military may actually be accepted as the norm and may no longer be as disruptive as in previous years. A systematic review by Blakely, Hennessy, Chung \& Skirton (2012) examining the coping mechanisms of military spouses, who were stationed abroad, suggested that ability to adapt to change is dependent on a combination of the families' innate qualities and the families' propensity to genuinely engage in a social support network.

Despite the fact that the sample size for this major project was larger than expected, several limitations were identified. Some limitations could be related to the TICS-LE tool itself since it was recently translated from German into English and this study represents the first use of the English version. (Additional studies using the English 
version of the tool can help clarify this question.) Additionally, due to the novelty of using this tool with an English speaking population, no current cut-off scores exist for a normative English speaking sample making it difficult to compare the scores from this study's sample with normative scores for chronic stress. Since eight respondents were willing to fill out the demographic information related to this study, but then apparently closed the browser when TICS-LE scale appeared, it is unclear whether they found the survey too lengthy to complete easily.

Other limitations of this major project arose from the methodology. In keeping with previous research studies (Green et al., 2013; Padden et al., 2011; Joseph \& Afifi, 2010), men were excluded from the study participants. With the recent advent of woman in combat roles, more male spouses may find themselves in a similar set of circumstances that had once been reserved for female military spouses. Furthermore, men may experience the stressors of being military spouses in unique ways. Potentially, male military spouses could have more difficulty resolving and coping with a lifestyle that is divergent from traditional gender roles. In addition, male military spouses could perceive there is less social support or be apprehensive about participating in traditional support structures that predominantly consist of women.

In the current literature, it has been difficult to recruit male spouses in sufficient numbers to achieve statistical significance; thus, an in-depth analysis of the unique stressors and challenges presented to male military spouses has not been performed. In fact, in Mansfield et al.'s (2010) study, which examined whether prolonged deployment of a military member correlated with the advent of psychological disease in military 
spouses, the population of male military spouses studied demonstrated such a dissimilar pattern of variance from the female military spouses that male spouses were excluded from the study. Results such as these, suggest that stressors and challenges experienced by male military spouses may be unique and possibly profoundly difficult yet, are poorly understood by researchers.

There are also very few studies of the stressors and challenges faced by military spouses of racial minorities and other multicultural groups in the current literature, which tends to over-represent Caucasian woman. Another limitation present in this major paper project is that demographic questions regarding race were not included as variables in the study. For this reason, there is no way to know if any racial minorities participated in the study. Clearly, with multicultural issues being critically important to social science researchers, participants with diverse backgrounds should be included in future studies.

Finally, Coast Guard spouses were excluded due to the distinctive and divergent role of the Coast Guard, which differs from the other armed forces. Currently, anecdotal evidence suggests that although the mission of the Coast Guard is different from the other armed forces, Coast Guard military spouses may have similar stressors, such as frequent relocations. Therefore, in retrospect, it may have been useful to include this group in the inclusion criteria. Arguably, because the Coast Guard becomes absorbed into the U.S. Navy during times of war, Coast Guard spouses may not receive the individual recognition that they desire, which may incur feelings of being marginalized. Understanding the structure and potential stressors of the armed forces can be difficult because "the armed forces maintain their own diverse cultural, demographic, and 
personal constructs," (Lowe et al., 2012, p. 17), which researchers may struggle to fully comprehend. 


\section{Recommendations and Implications for Advanced Nursing Practice}

Advance practice nurses (APRNs), whether working in the military or in the civilian world, should be cognizant of the potential struggles military spouses and military families face. Current literature shows that stressors that arise with the military lifestyle can influence physical (Burton et al., 2009) and psychological well-being (Mansfield et al., 2010), as well as impair family functioning (Lowe et al., 2012); therefore, the APRN may find that having ongoing collegial relationships with other disciplines such as psychologists, psychiatrists, counselors and primary care providers for referrals may be helpful. Advance practice nurses, especially mental health nurse clinicians, should be mindful that the military has a unique cultural structure that has historically been distrusting towards mental health practitioners (Hoge et al., 2008). Military members and military spouses may harbor feelings of ambivalence, distrust or shame towards seeking any type of mental health services. Advance practice nurses should also concentrate on ensuring a client's safety, especially if mental health issues are suspected. Screening for suicidal ideation or other mental illnesses that pose a threat to the safety of the client or others is of the utmost importance. Furthermore, monitoring the effects of any interventions, such as responses to antidepressants, is a crucial intervention to ensure safety and quality.

Military families may be able to deploy to foreign or remote areas with military spouses. Technology, such as a uniform electronic medical record, may prove helpful to track or flag military spouses or families who frequently relocate. Computer technology that allows the clinician and client to see each other face-to-face is already being used to 
conduct interviews with sailors suffering from addiction in the Navy while they are on active duty military assignments (Alcoholism \& Drug Abuse Weekly, 2010). Similar technology could be used for mental health services, such as counseling for military spouses currently living in remote areas.

Military spouses play a pivotal role in the family balancing the needs and responsibilities of the military member and the children in an effort to hold the family together (Green et al., 2013). Currently, social support and resiliency are two areas, which have been identified to mitigate military life stressors (Blakely et al., 2012). Luthar et al. (2000) suggested that the concept of resilience, which is defined as "dynamic process wherein individuals display positive adaptation despite experiences of significant adversity or trauma", is not just a quality possessed by certain individuals but more of a tangible process that can be learned over time (p. 858). The Comprehensive Soldier and Family Fitness Program is large military program designed to teach resiliency skills to military members and military families, however, the effectiveness of this program has been somewhat controversial (Griffith \& West, 2013). Membership in military spouse groups is one useful way that military spouses can become connected to social networks. However, as stated above, it is unclear whether these informal networks provide the high quality relationships that allow military spouses to overcome feelings of social isolation. Easy access to the internet and social media may be one way to prevent social isolation in military spouses.

Another more difficult to institute intervention that could take place on the leadership level of the military would be to periodically guarantee placement of military 
families close to family networks. Currently, the military makes an effort to relocate military families to a place of their choosing, however, military families are not given assurances that they will get the requested destination. Implementation of guaranteeing placement would take considerable effort on the part of the Armed Services and policymakers, but policy makers should concentrate efforts on ameliorating situations, which have been known to be most deleterious to military spouses and families.

Another example of the extreme stress experienced by military families is the lengthy deployments that have been associated with mental illness in military spouses (Mansfield et. al, 2010). However, in times of war and with only volunteer military servicemen limiting lengthy deployments may be difficult. Another effort that might be more useful would be to enforce a career limit on deployments; this might curb the number of years the military members would be absent from the family unit.

In conclusion, military spouses face a number of challenges associated with being a military spouse. Yet, in this study, the military spouses surveyed seemed to display relatively lower levels of stress than originally anticipated based on other studies found in the literature. This unexpected result could be related to the demographic profile of the respondents. Several limitations prevent generalizability of the results, but the study results highlight the need for the APRN to be aware of the stressors and potential pitfalls that military spouses and families experience. Advance practice nurses need to utilize technology and common sense treatment modalities to treat and monitor military spouses. Furthermore, APRN's and other clinicians who are active in military communities and policy making could be tasked with changing military practices that have been shown to 
be harmful to military families. 


\section{References}

Asbury, E. T., \& Martin, D. (2011). Military deployment and the spouse left behind. The Family Journal: Counseling and Therapy for Couples and Families, 20, 45-50.

Burton, T., Farley, D., \& Rhea, A. (2009). Stress-induced somatization in souses of deployed and nondeployed servicemen. American Academy of Nurse Practitioners, 21, 332-339.

Blakely, G., Hennessy, C., Chung, M.C., \& Skirton, H. (2012). A systematic review of the impact of foreign postings on accompanying spouses of military personnel. Nursing and Health Sciences, 14, 121-132.

DeBurgh, H. T., White, C. J., Fear, N. T., \& Iversen, A. C. (2011). The impact of deployment to Iraq or Afghanistan on partners and wives of military personnel. International Review of Psychiatry, 23, 192-200.

Green, S., Nurius, P. S., \& Lester, P. (2013). Spouse psychological well-being: A keystone to military family health. Journal of Human Behavior in the Social Environment, 23, 753-768.

Griffith, J., \& West, C. (2013). Master resilience training and its relationship to individual well-being and stress buffering among army national guard soldiers. Journal of Behavioral Health Sciences \& Research. 40(2), 140-155.

Groer, M., Meagher, M.W., \& Kendall-Tackett, K. (2010). An overview of stress and immunity. In K. Kendall-Tackett (Ed.).The psychoneuroimmunology of chronic disease (pp. 9-22). Washington, D.C.: American Psychological Association. 
Hagedoorn, M., Kuijer, P., Buunk, B., DeJong, G., \& Wobbes, T. (2000) Marital satisfaction in patients with cancer: Does support from intimate partners benefit those who need it the most? Health Psychology, 19, 274-282.

Herzog, J. R., Everson, R. B., \& Whitworth, J. D. (2011). Do secondary trauma symptoms in spouses of combat-exposed National Guard soldiers mediate impacts of soldiers' trauma exposure on their children. Journal of Child Adolescent Social Work, 28, 459-473.

Hiew, C. C. (1992). Separated by their work: Families with fathers living apart. Environment and Behavior, 24, 206-225.

Hoge, C.W., Castro, C.A. Messer, S.C., McGurk, D., Cotting, D.I., \& Koffman, R.L. (2008, July-September).Combat duty in Iraq and Afghanistan, mental health problems and barriers to care. The Army Medical Department Journal, 7-17.

Joseph, A. L., \& Afifi, T. D. (2010). Military wives' stressful disclosures to their deployed husbands: The role of protective buffering. Journal of Applied Communication Research, 38, 412-434.

Lapp, C. A., Taft, L. B., Tollefson, T., Hoepner, A., Moore, K., \& Divyak, K. (2010). Stress and coping on the home front: Guard and reserve spouses searching for a new normal. Journal of Family Nursing, 16(1), 45-67.

Lowe, K. N., Adams, K. S., Browne, B. L., \& Hinkle, K. T. (2012). Impact of military deployment on family relationships. Journal of Family Studies, 18, 17-27. 
Luthar, S. S., Cicchetti, D. (2000). The construct of resilience: Implications for interventions and social policies. Developmental Psychopathology, 12(4), 857885.

Mansfield, A. J., Kaufman, J. S., Marshall, S. W., Gaynes, B. N., Morrisey, J. P., \& Engel, C. C. (2010). Deployment and the use of mental health services among U.S. Army wives. The New England Journal of Medicine, 362(2), 101-109.

McCubbin, H. I., \& Patterson, J. M. (1982). Family adaptation to crises. In H. I. McCubbin, A. E. Cauble, \& J. M. Patterson (Eds.), Family stress, coping and social support (pp. 26-47). Springfield: Charles C. Thomas.

McEwen, B. S. (1998, January). Protective and damaging effects of stress mediators. New England Journal of Medicine, 338, 171-179. doi:10.1056/NEJM199801 153380307

National Military Family Association.(2007). Education \& the military spouse: The long road to success [Research report]. Retrieved from National Military Family Association:http://www.militaryfamily.org/assets/pdf/Spouse_Education_ Report_FINAL.pdf

Padden, D. L., Connors, R. A., \& Agazio, J. G. (2011, January). Determinants of healthpromoting behaviors in military spouses during deployment separation. Military Medicine, 176, 26-34.

Program to help sailors with web-based recovery program. (2010, October). Alcoholism \& Drug Abuse Weekly, 22(39), 7-8. doi: 10.1002/adaw.20253 
Rice, V. H. (2012) Theories of stress and its relationship to health. In V. H. Rice (Ed.), Handbook of stress, coping and health: Implications for nursing research, theory and practice (pp. 22-42). Detroit, Michigan: SAGE Publications.

Schulz, P. Schlotz, W. \& Becker, P. (2011). The Trier Inventory of Chronic Stress (TICS)-Manual (W. Schlotz, supported by Google Translate, Trans.) Gottingen, Germany: Hogrefe (original work published 2004).

U.S. Department of Defense. (n. d.-a). The United States Military Officer Rank Insignia. Retrieved from http://www.defense.gov/about/insignias/officers.aspx

U.S. Department of Defense. (n. d.-b). The United States Military Enlisted Rank Insignia. Retrieved from http://www.defense.gov/about/insignias/enlisted.aspx

Wheeler, A. R., \& Torres Stone, R. A. (2009, November). Exploring stress and coping strategies among National Guard spouses during times of deployment: A research note. Armed Forces \& Society, 36, 545-557. 


\section{Appendix A}

Table 1

Demographic information of military spouses

\begin{tabular}{|c|c|c|c|}
\hline & & $\mathbf{N}$ & Percent (\%) \\
\hline \multirow{5}{*}{$\begin{array}{l}\text { Length of } \\
\text { Relationship }\end{array}$} & Less than one year & 1 & 1.4 \\
\hline & $1-5$ years & 9 & 12.7 \\
\hline & $6-10$ years & 18 & 25.4 \\
\hline & $11-20$ years & 32 & 45.1 \\
\hline & 21 plus years & 11 & 15.5 \\
\hline \multirow{3}{*}{$\begin{array}{l}\text { Employment } \\
\text { Status of military } \\
\text { spouse }\end{array}$} & Not working & 45 & 63.4 \\
\hline & Part-Time & 17 & 23.9 \\
\hline & Full-Time & 9 & 12.7 \\
\hline \multirow{4}{*}{$\begin{array}{l}\text { Number of } \\
\text { Children }\end{array}$} & None & 14 & 19.7 \\
\hline & $1-2$ & 34 & 47.9 \\
\hline & $3-4$ & 21 & 29.6 \\
\hline & 5 or more & 2 & 2.8 \\
\hline \multirow[t]{6}{*}{ Education Level } & High school & 1 & 1.4 \\
\hline & Some College & 7 & 9.9 \\
\hline & Associate Degree & 4 & 5.6 \\
\hline & Bachelor's Degree & 34 & 47.9 \\
\hline & Master's Degree & 20 & 28.2 \\
\hline & Doctorate & 5 & 7 \\
\hline \multirow{2}{*}{$\begin{array}{l}\text { Enlisted vs. } \\
\text { Commissioned }\end{array}$} & Enlisted & 4 & 5.6 \\
\hline & Commissioned & 67 & 94.4 \\
\hline
\end{tabular}




\begin{tabular}{|c|c|c|c|}
\hline & & $\mathrm{N}$ & Percent (\%) \\
\hline \multirow[t]{4}{*}{ Branch of military } & Army & 18 & 25.4 \\
\hline & Navy & 41 & 57.7 \\
\hline & Marines & 3 & 4.2 \\
\hline & Air Force & 9 & 12.7 \\
\hline \multirow{2}{*}{$\begin{array}{l}\text { Active duty spouse } \\
\text { currently deployed }\end{array}$} & Yes & 7 & 9.9 \\
\hline & No & 64 & 90.1 \\
\hline \multirow{4}{*}{$\begin{array}{l}\text { Times Active Duty } \\
\text { Spouse has Been } \\
\text { Deployed }\end{array}$} & None & 4 & 5.6 \\
\hline & 1-2 times & 16 & 22.5 \\
\hline & 3-4 times & 29 & 40.8 \\
\hline & 5 or more times & 22 & 31 \\
\hline \multirow{4}{*}{$\begin{array}{l}\text { Total Length of } \\
\text { Deployment }\end{array}$} & None & 5 & 7 \\
\hline & $1-2$ years & 31 & 43.7 \\
\hline & $3-4$ years & 26 & 36.6 \\
\hline & 5 or more years & 9 & 12.7 \\
\hline
\end{tabular}




\section{Appendix B}

Table 2

List of 10 factors and associated TICS-LE item numbers

\begin{tabular}{|c|c|c|}
\hline & Factor & TICS-LE Item Number \\
\hline 01 & work overload & $\begin{array}{l}01,04,14,27,38,44, \\
50,54\end{array}$ \\
\hline 02 & social overload & $07,19,28,39,49,57$ \\
\hline 03 & pressure to perform & $\begin{array}{l}08,12,14,22,23,30,32 \\
40,43\end{array}$ \\
\hline 04 & work discontent & $\begin{array}{l}05,10,13,21,37,41,48, \\
53\end{array}$ \\
\hline 05 & $\begin{array}{l}\text { excessive demands at } \\
\text { work }\end{array}$ & $03,20,24,35,47,55$ \\
\hline 06 & lack of social recognition & $02,18,31,46$ \\
\hline 07 & social tensions & $06,15,26,33,45,52$ \\
\hline 08 & social isolation & $11,29,34,42,51,56$ \\
\hline 09 & chronic worrying & $9,16,25,36$ \\
\hline 10 & chronic stress & $\begin{array}{l}09,16,18,25,31,35,36, \\
38,44,47,54,57\end{array}$ \\
\hline
\end{tabular}




\section{Appendix C}

Table 3

Descriptive statistics on the eight factors of the TICS-LE

\begin{tabular}{|c|c|c|c|c|c|c|}
\hline & $\begin{array}{l}\text { Chronic } \\
\text { Worrying } \\
\text { Scale }\end{array}$ & \multicolumn{2}{|c|}{$\begin{array}{l}\text { Social } \\
\text { Isolation } \\
\text { Scale }\end{array}$} & $\begin{array}{l}\text { Social } \\
\text { Tensions } \\
\text { Scale }\end{array}$ & $\begin{array}{l}\text { Lack of } \\
\text { Social } \\
\text { Recognition } \\
\text { Scale }\end{array}$ & $\begin{array}{l}\text { Excessive } \\
\text { Demands at } \\
\text { Work Scale }\end{array}$ \\
\hline $\mathbf{N}$ & 71 & 71 & & 71 & 71 & 71 \\
\hline Mean & 1.71 & 2.00 & & 1.03 & 1.35 & 1.17 \\
\hline Median & 1.50 & 1.83 & & 0.8 & 1.25 & 1.16 \\
\hline Mode & 2.00 & 1.33 & & 0.67 & 1.25 & 1.5 \\
\hline SD & 1.02 & 1.06 & & 0.57 & 0.73 & 0.63 \\
\hline Variance & 1.04 & 1.12 & & 0.33 & 0.53 & 0.4 \\
\hline \multirow[t]{2}{*}{ Range } & 3.75 & 4.00 & & 3.00 & 3.00 & 2.80 \\
\hline & \multicolumn{2}{|c|}{$\begin{array}{l}\text { Work } \\
\text { Discontent }\end{array}$} & \multicolumn{2}{|c|}{$\begin{array}{l}\text { Pressure to } \\
\text { Perform }\end{array}$} & $\begin{array}{l}\text { Social } \\
\text { Overload }\end{array}$ & $\begin{array}{l}\text { Work } \\
\text { Overload }\end{array}$ \\
\hline $\mathbf{N}$ & \multicolumn{2}{|l|}{71} & \multicolumn{2}{|l|}{71} & 71 & 71 \\
\hline Mean & \multicolumn{2}{|l|}{1.52} & \multicolumn{2}{|c|}{1.28} & 2.05 & 1.60 \\
\hline Median & \multicolumn{2}{|l|}{1.5} & \multicolumn{2}{|c|}{1.33} & 2.00 & 1.50 \\
\hline Mode & \multicolumn{2}{|l|}{1.00} & \multicolumn{2}{|c|}{0.33} & 1.83 & 1.50 \\
\hline SD & \multicolumn{2}{|l|}{0.66} & \multicolumn{2}{|c|}{0.60} & 0.79 & 0.67 \\
\hline Variance & \multicolumn{2}{|l|}{0.44} & \multicolumn{2}{|c|}{0.37} & 0.63 & 0.45 \\
\hline Range & \multicolumn{2}{|l|}{3.00} & \multicolumn{2}{|c|}{2.33} & 3.83 & 3.38 \\
\hline
\end{tabular}

